\title{
The influence of proportion of Hereford breeding in a multibreed synthetic beef cattle population on birth weight and weaning weight
}

\author{
H. Skrypzeck, S.J. Schoeman and G.F. Jordaan \\ Dept of Animal Sciences, University of Stellenbosch, P Bag X1, Matieland, 7602
}

\section{Introduction}

The development of synthetic breeds is a topic of major importance for the improvement of beef cattle. Combining different breeds in order to create a "new breed" provides an excellent opportunity to exploit breed complementarity (breed additive differences) and heterosis for a variety of traits. It also provides the opportunity to optimize additive genetic composition for composite superiority, incorporating climatic adaptability and performance traits into a "new breed" that is in harmony with the production environment and market requirements (Lin, 1996; Schoeman, 1999). The aim of this study was to assess the contribution of the Hereford breed in a multibreed beef cattle herd in an intensive production system and to obtain the desired proportion of Hereford $(\mathrm{H})$ therein using simple regression procedures on direct breeding values (DBV), maternal breeding values (MBV) and phenotypic values for birth weight (BW) and weaning weight (WW).

\section{Materials and Methods}

Data was obtained from a multibreed (14 breeds) synthetic beef cattle population, managed under intensive irrigated grazing conditions by the Johannesburg Metropolitan Council. The data set consisted of $52628 \mathrm{BW}$ and WW records collected from 1968 and 1993. Calves born between 1968 and 1993 had varying levels of $\mathrm{H}$ genes, with an average of $19.3 \%$. Data was analysed using the VCE 4.2 .5 package of Groeneveld (1998) and fitting only unitrait models to the data. These models accounted for $\mathrm{h}^{2}{ }_{\mathrm{a}}$ and $\mathrm{h}^{2}{ }_{\mathrm{m}}$ and $\mathrm{r}_{\mathrm{am}}$ and were subsequently used to predict individual BV of each animal for each trait. The model fitted to each trait and trait means are presented in Table 1. Individual adjusted (for fixed effects) phenotypic values (or residual mean squares) for each trait was also estimated (SAS, 1993). The means of individual DBV, MBV and phenotype of BW and WW were regressed on proportion of H breeding, using Excel (Office 97, 1998).

Table 1 Statistical models for unitrait analyses of BW, WW and CE.

\begin{tabular}{|c|c|c|c|c|c|}
\hline \multirow{3}{*}{\begin{tabular}{|l|} 
Traits Effects \\
Year
\end{tabular}} & \multirow[t]{3}{*}{ Type } & \multirow{2}{*}{$\begin{array}{c}\text { Number } \\
\text { of levels }\end{array}$} & \multicolumn{3}{|c|}{ Traits } \\
\hline & & & & & WW \\
\hline & & 25 & $\mathrm{x}$ & $\bar{x}$ & \\
\hline Farm & Fixed & 2 & $\mathrm{x}$ & $\mathrm{x}$ & \\
\hline Sex of calf & Fixed & 2 & $\mathrm{x}$ & $\mathrm{x}$ & \\
\hline Season of birth & Fixed & 2 & $\mathrm{x}$ & $\mathrm{x}$ & \\
\hline Dam age & Covariate & 1 & $\mathrm{x}$ & $\mathrm{x}$ & \\
\hline Weaning age of calf & Covariate & 1 & $\mathrm{x}$ & & $\mathrm{x}$ \\
\hline Maternal & Animal & 57078 & $\mathrm{x}$ & & $\mathrm{x}$ \\
\hline Animal & Animal & 57078 & $\mathrm{x}$ & & $\mathrm{x}$ \\
\hline $\begin{array}{l}\text { Means } \\
207.3\end{array}$ & & & & & .5 \\
\hline
\end{tabular}

\section{Results and Discussion}

Regressions of DBV, MBV and phenotypic values for BW and WW on proportion of $\mathrm{H}$ breeding are presented in Figure $1(\mathrm{a}-\mathrm{f})$. DBV and MBV of BW decreased with an increase in proportion of $\mathrm{H}$ contribution. The DBV of BW is important because it can have a mayor influence on calving ease, indicating that less calving difficulties would be expected with an increase in the proportion of $\mathrm{H}$. The phenotypic value of $\mathrm{BW}$ decreased with an increase in proportion of $\mathrm{H}$, reaching a minimum of $35 \mathrm{~kg}$ at a proportion of 0.51 , whereafter it increases again (Fig. 1(c)). DBV, MBV and phenotypic values of WW decreased with an increase in $\mathrm{H}$ contribution. Relative to the other breeds in the composite, increasing $\mathrm{H}$ contribution decreases the genetic potential of the composite. The MBV of WW predicts the milk production of an animal and also reflects the milking ability of the animal's 
Short paper and poster abstracts: $38^{\text {th }}$ Congress of the South African Society of Animal Science

daughters (Bradfield \& Erasmus, 1999), showing in Fig. 1(e) a decrease in WW with and increase in $H$ contribution. It is also known that the $\mathrm{H}$ is a low milk producing breed (Jenkins \& Ferrell, 1992). In most other investigations into crossbreeding parameters, negative MBV were reported for WW (Cunningham \& Magee, 1988; Schoeman et al., 1993.) The direct effect was positive in some investigations (Cunningham \& Magee, 1988), while it was negative in others (Alenda et al., 1980), depending on the breeds it was compared with. In this study, DBV for WW are negatively associated with proportion of $\mathrm{H}$, most likely because of the large contribution of large frame-sized breeds such as the Simmentaler and Charolais to the composition of the herd (Schoeman et al., submitted). In earlier reports (Schoeman et al., 1993) it was found that the large negative maternal effect overrides a positive direct effect, thus leading to the decreased WW with increasing proportion of $\mathrm{H}$, despite a positive direct effect in these studies.
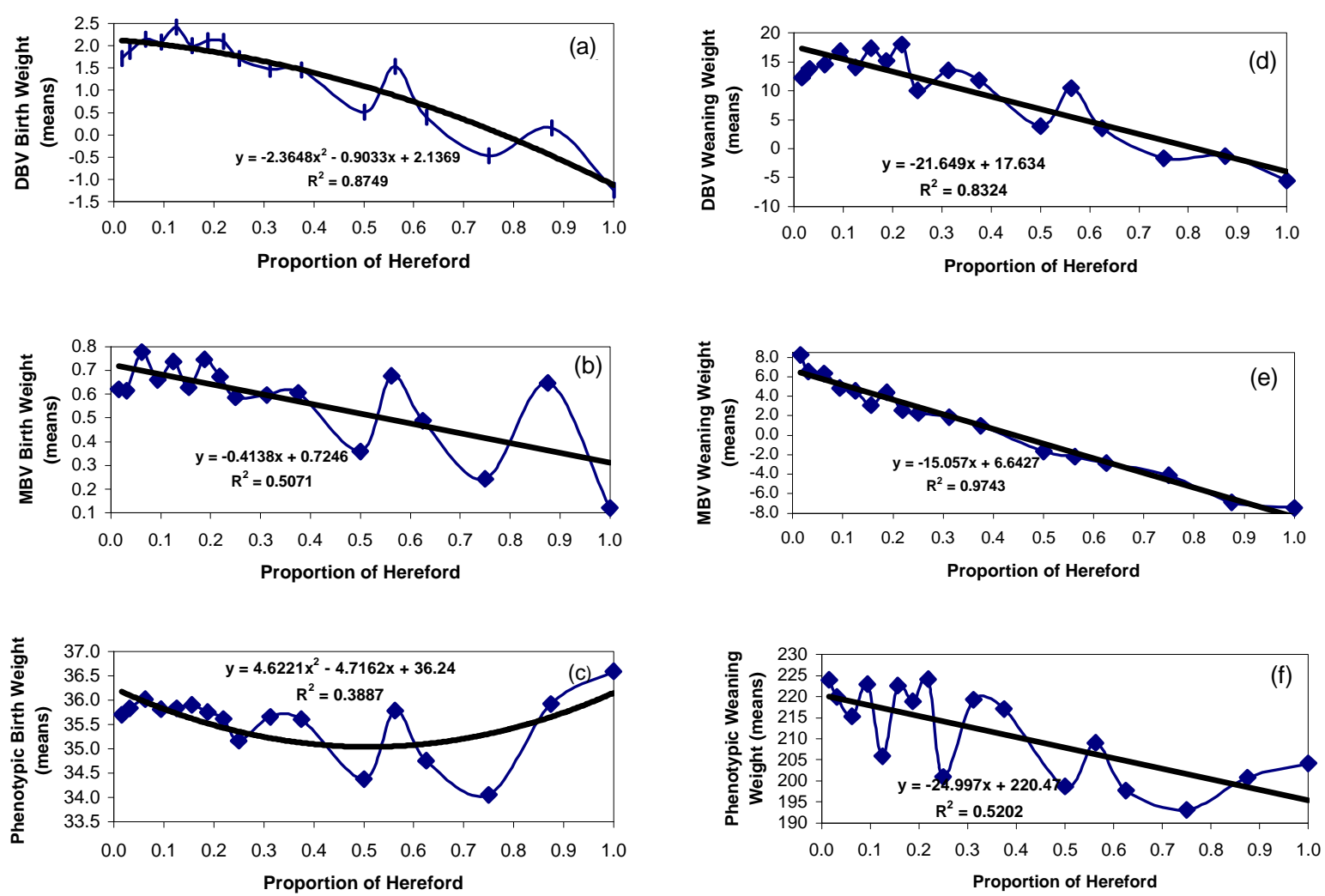

Figure 1 Regressions of (a) DBV of BW, (b) MBV of BW, (c) Phenotypic value of BW, (d) DBV of WW, (e) MBV of WW and (f) Phenotypic value of WW on proportion of Hereford breeding.

\section{Conclusion}

These results clearly illustrated a decrease in performance levels and breeding values with increasing $\mathrm{H}$ contribution. It indicated that no desired optimal $\mathrm{H}$ proportion was evident in this multibreed beef cattle herd within this specific environment.

\section{References}

Alenda, R. et al., 1980. J. Anim. Sci. 50, 226.

Bradfield, M.J. \& Erasmus, G.J., 1999. Beef Breeding in South Africa. ARC (Animal Improvement Institute), Irene. pp.37.

Cunningham, B.E. \& Magee, W.T., 1988. Can. J. Anim. Sci. 68, 83.

Groeneveld, E., 1998. VCE-4,User's guide and Reference manual. Insitute of Anim. Husbandry and

Anim. Behav., Mariensee, Germany.

Jenkins, T.G. \& Ferrell, C.L., 1992. J. Anim. Sci. 70, 1652.

Lin, C.Y., 1996. J. Anim. Sci. 74, 1447.

SAS, 1993. SAS/STAT User's guide (Version 6). SAS Institute Inc. Cary, N.C.

Schoeman, S.J., 1999. Beef Breeding in South Africa. ARC (Animal Improvement Institute), Irene. pp.43. 
(C) South African Society of Animal Science

Short paper and poster abstracts: $38^{\text {th }}$ Congress of the South African Society of Animal Science Schoeman, S.J., 1996. S. Afr. J. Anim. Sci. 26, 15.

Schoeman, S.J. et al., 1993. S. Afr. J. Anim. Sci. 23, 61.

Schoeman, S.J. et al., S. Afr. J. Anim. Sci. submitted. 